\title{
A IMPORTÂNCIA DO GESTOR ESCOLAR NA INCLUSÃO DE ALUNOS COM NECESSIDADES ESPECIAIS NA ESCOLA
}

\author{
Alex Sandro Santos ${ }^{1}$
}

\begin{abstract}
RESUMO: Este trabalho faz uma breve discussão sobre alguns aspectos relacionados à Importância do Gestor Escolar na Inclusão de alunos com necessidades especiais na escola. Muito se tem falado a respeito dos direitos das pessoas com necessidades educacionais especiais, porém percebe-se que ainda existem muitos obstáculos para a sua efetiva inclusão. O objetivo deste artigo é contribuir para a reflexão sobre o papel do gestor pedagógico frente ao processo de construção de escolas cada vez mais inclusivas. Para tanto o estudo primou por pesquisa bibliográfica, as quais servirão para refletir algumas hipóteses relacionadas ao papel do gestor na inclusão escolar. Sage (2009), Páez (2001) e Glat (2007) são os principais autores que fundamentaram esta pesquisa. Observou-se durante a pesquisa que são muitas as barreiras, falta de formação e informação de alguns gestores e acima de tudo, o preconceito, ainda tem feito com que estes seres humanos ocupem papéis muito aquém do necessário para se ter uma boa qualidade de ensino. Neste contexto o papel do gestor é sem dúvidas promover a transformação nas práticas organizacionais da escola, através de estudos e reflexões, além de promover o envolvimento de todos a respeito de questões pedagógicas, para derrubar os entraves da educação inclusiva e eliminar as barreiras que possam impedir o processo de escolarização, visando à construção de formas mais dignas e inclusivas dos referidos alunos.
\end{abstract}

Palavras-chave: Gestor; Inclusão Escolar; Necessidades Especiais.

\section{THE IMPORTANCE OF THE SCHOOL MANAGER IN THE INCLUSION OF STUDENTS WITH SPECIAL NEEDS IN SCHOOL}

\begin{abstract}
This work is a brief discussion of some aspects related to the Manager Importance of School in the inclusion of students with special needs at school. Much has been said about the rights of people with special educational needs, but it is clear that there are still many obstacles to their effective inclusion. The purpose of this article is to contribute to the reflection on the role of the pedagogical front manager in the process of building more inclusive schools. For this study it was conspicuous by literature, which serve to reflect certain assumptions related to the role of the manager in the school inclusion. Sage (2009), Paez (2001) and Glat (2007) are the main authors that supported this research. It was observed during the study that there are many barriers, lack of training and information of some managers and above all prejudice, yet has made these humans occupy roles far short of the need to have a good quality education. In this context the role of the manager is no doubt promote transformation in
\end{abstract}

\footnotetext{
${ }^{1}$ Mestrando em Ciências Sociais pela Universidade Estadual de Maringá - UEM. Professor no Instituto Educacional Adventista Paranaense - IAP. Professor na Faculdade Santa Maria da Glória - SMG Maringá. E-mail: alexsoldy@hotmail.com
} 
school organizational practices through study and reflection, and promote the involvement of all about pedagogical issues, to bring down the barriers of inclusive education and remove barriers that may prevent the schooling process in order to build more dignified and inclusive forms of these students.

Keywords: Manager; School Inclusion; Special Needs.

\section{INTRODUÇÃO}

A instituição escolar é um sistema que opera através de padrões que estabelecem e constituem sua função social, que está relacionada à construção de conhecimento, bem como, repasse de informações, socialização e instrumentalização para exercícios de cidadania, sendo capaz de mudar e flexibilizar seus padrões internos para garantir seu espaço social. A escola hoje deve ser um ambiente acolhedor e prazeroso, que proporcione a todos os alunos o acesso, a permanência, bem como, o aprendizado com qualidade, tanto para os alunos com necessidades especiais, quanto para todos os demais, independentemente de suas características físicas e culturas.

Para Penaforte, (2009) o desafio do gestor pedagógico é desenvolver estratégias instrucionais que possibilitem respostas às variadas necessidades e situações de aprendizagem. Assim as formas de realizar a inclusão têm ocorrido das mais diversas formas e o gestor escolar apresenta grande importância, sendo necessário que o mesmo busque uma atuação baseada na diversidade em conseqüência da liderança que exerce.

Sabemos a importância dos professores, porém não podemos menosprezar o gestor, que exerce um papel de essencial relevância na perspectiva de uma educação mais inclusiva, pois todos que compõem este ambiente escolar, inclusive os professores estarão seguindo e analisando suas ações. Neste contexto tendo em vista as novas regras e demandas que a escola vem enfrentando, o gestor caracteriza - se como sendo uma das peças mais importantes da conscientização para superar todas as limitações na busca de uma atuação mais efetiva.

Sendo assim o objetivo do trabalho é abordar estudos relacionados à inclusão de alunos que apresentam necessidades educacionais especiais nas escolas e, contribuir para a reflexão sobre o papel do gestor pedagógico frente ao processo de construção de escolas inclusivas. É necessário refletir no que se refere à real inclusão das pessoas com necessidades educacionais especiais, como um todo, e o que ainda esteja impedindo ou 
dificultando, a presença ou permanência destes alunos no meio social e especialmente neste caso, sua efetiva inclusão nas escolas.

\section{INCLUSÃO ESCOLAR}

Entende-se como inclusão escolar o processo de acolher com respeito todas as pessoas, sem exceções, no sistema de ensino, independentemente de cor, classe social e condições físicas e psicológicas. O termo é empregado normalmente à inclusão educacional de pessoas com deficiência física e mental.

Para Carvalho (2006, p. 36) a educação inclusiva pode ser explicada como um movimento contra qualquer tipo de exclusão que venha ocorrer dentro dos espaços educacionais do ensino regular.

A inclusão educacional hoje em dia é um assunto de grande destaque, e é percebida através de uma educação que satisfaça às necessidades básicas dos alunos no desenvolvimento pleno das potencialidades, que permita uma vida mais estável e saudável para esse educando na interação escolar como um todo.

A inclusão escolar possibilita atitudes que garantam o acesso e permanência do aluno com deficiência no ensino regular de igual para igual com os demais alunos. A educação inclusiva é uma temática renovadora para as escolas, isso porque ela procura ampliar os horizontes e a participação dos alunos com necessidades especiais nos processos de ensino e de aprendizagem. Trata-se de uma mudança na estrutura educacional para a recepção do aluno com necessidades educativas especiais.

Ainda que a realidade esteja longe de se concretizar afirma (GARCIA, 2007), para se alcançar os ideais de uma educação para todos, o fundamental é tornar efetivas as políticas existentes, para que mecanismos legais possam concretizar o direito de todas as crianças conviverem e aprenderem juntas em espaços regulares de ensino.

Hoje, o assunto inclusão consiste em grande destaque e mostra a necessidade de uma educação que satisfaça às necessidades básicas dos alunos e no seu desenvolvimento, que permita ao educando participar das ações da escola, ter acesso ao seu espaço. Usufruir dos seus serviços, por exemplo, é algo que deve estar aberto aos alunos especiais, pois estes não podem sentir-se limitados ou ainda deixar de desenvolverem atividades que os demais alunos desenvolvam. 
Segundo Páez (2001, p. 33) a inclusão pode trazer benefícios incontestáveis para o desenvolvimento da pessoa com deficiências, desde que sejam oferecidos na escola regular, pois este é um momento decisivo na vida do aluno. A educação inclusiva reconhece as diferenças e limitações existentes de cada aluno e respeita o que tange a tratar os desiguais no limite de suas desigualdades, de forma a garantir que cada aluno se sinta acolhido e se sinta parte da comunidade escolar.

Com o advento do processo educacional inclusivo, fica claro que o papel das escolas não é somente desenvolver um novo processo educacional de uma forma inclusiva, mas também o desenvolvimento de uma nova cultura escolar, embasada nos direitos humanos, em especial, ao direito de todos os alunos se beneficiarem de um ensino de qualidade, tendo como princípio norteador básico a igualdade.

Segundo Glat (2007):

\begin{abstract}
A educação inclusiva significa um novo modelo de escola em que é possível o acesso e a permanência de todos os alunos, e onde os mecanismos de seleção e discriminação, até então utilizados, são substituídos por procedimentos de identificação e remoção das barreiras para a aprendizagem. Para tornar-se inclusiva a escola precisa formar seus professores e equipe de gestão, e rever formas de interação vigentes entre todos os segmentos que a compõem e que nela interferem, precisa realimentar sua estrutura, organização, seu projeto político pedagógico, seus recursos didáticos, metodologias e estratégias de ensino, bem como suas práticas avaliativas (GLAT 2007, p. 16).
\end{abstract}

Atualmente a perspectiva educacional propõe que um bom educador faça a diferença, e para tanto, cada um deles deve buscar aprendizado, capacitações e qualificação, de forma que se contribua para uma prática diferenciada, desenvolvendo uma educação baseada na afetividade e na superação de limites, sendo que a palavra principal que deve ser sempre lembra é respeito entre as diferenças.

Diante do exposto percebe-se que para esta inclusão seja feita de forma eficaz o gestor tem grande importância sendo necessário que ele busque sua atuação baseada na diversidade e respeito. O gestor é capaz de garantir abertura de novos espaços à transformação do cotidiano escolar em consequência da liderança que exerce, neste sentido deve ser o primeiro a ter consciência da importância da escola inclusiva implementando práticas que favoreçam a igualdade. 


\section{A GeStÃo ESCOLAR E SUAS CONTRIBUiÇões NO PROCESSO INCLUSIVO.}

A Gestão do ensino Brasileiro tem sido dedicada muita atenção vem ampliando o enfoque que antes era apenas administrativo, pois os problemas educacionais são cada vez mais complexos, e precisa ser tratado como visão global e abrangente assim como ação articulada, dinâmica e participativa.

A preocupação que hoje é imposta à escola como uma das principais instituições que são responsáveis pela efetivação do processo inclusivo, indica que tais problemas ainda necessitam de ajustes para ser eliminados da agregação escola e traz a da gestão escolar e demonstra que a mesma precisa superar a discussão falta de orientação e de liderança clara e competente, que devem ser exercida sobre o enfoque dos princípios educacionais participativos, de teoria metodológica, voltadas para a organização do trabalho em educação, com métodos estratégicos globalizados para vencer tal imposição.

Às vezes, é suficiente uma conversa informal com alguns professores para perceber seus medos, descrédito e insegurança com relação ao atendimento do aluno com necessidades especiais. Fatos esses que geram entre professores resistência à inclusão.

Para Zimermann (2008):

\footnotetext{
A instituição escolar precisa redefinir sua base de estrutura organizacional destituindo-se de burocracias e reorganizando grades curriculares, proporcionando maior ênfase à formação humana dos professores, e afinando a relação família escola, que a educação inclusiva tem força transformadora não somente para a educação, mas para uma sociedade inclusiva (ZIMERMANN, 2008, p.1).
}

O artigo 208 da Constituição Federal (1988) especifica que é dever do Estado garantir o atendimento educacional especializado aos portadores de deficiência, preferencialmente na rede regular de ensino condição que também consta no artigo 54 do Estatuto da Criança e do Adolescente (lei 8.069 no dia 13 de julho de 1990). Porém é comum até mesmo entre os meios educacionais não perceber o significado do ensino inclusivo que é acolher todas as pessoas, sem exceção, no sistema de ensino, independentemente de cor, classe social e condições físicas e psicológicas. O termo é 
associado mais comumente à inclusão educacional de pessoas com deficiência física e mental.

A inclusão educacional é uma questão muito presente nas escolas atualmente e o enorme preconceito que havia contra estas pessoas que apresentam algum tipo de deficiência física ou mental vem, felizmente, diminuindo gradativamente, mesmo ainda sendo necessários muitos ajustes e preparação dos governantes, sociedades e escolas.

Como comenta Padilha (2005) vê-se o surgimento da idéia de que é preciso garantir e estimular a participação de todos na sociedade, e também de reconhecer e desenvolver o potencial de cada cidadão e eliminar com isso, portanto, a discriminação ao portador de deficiência. Ou seja, se a escola é vista como o órgão que acaba por socializar os cidadãos, cabe a ela também tal obrigação no que se refere aos portadores de deficiência.

O papel da gestão escolar na construção da escola inclusiva é de suma importância, cabe ao Gestor escolar a implantação dos projetos e administração dos mesmos no que se refere a inclusão, porém a participação no processo inclusivo deve ser de toda a comunidade escolar. É comum que os professores temam inovação e assumam riscos que sejam encarados de forma negativa e com desconfiança pelos pares que estão aferrados aos modelos tradicionais. "O Gestor é de fundamental importância na superação dessas barreiras previsíveis e pode fazê-lo através de palavras e ações adequadas que reforçam o apoio aos professores”. (SAGE, 1999, p. 138).

Sage (1999, p. 129) analisa ainda que "a relação entre o gestor escolar e a educação inclusiva, reconhece que a prática dessa educação requer alterações importantes nos sistemas de ensino e nas escolas". Os anos se passaram e ainda se faz necessárias alterações no sistema de ensino no que refere ao processo inclusivo, os gestores escolares são essenciais nesse processo, pois lideram e mantêm a estabilidade do sistema. As mudanças apontadas para a construção da escola inclusiva envolvem vários níveis do sistema administrativo: secretarias de educação, organização das escolas e procedimentos didáticos em sala de aula.

A contribuição do Gestor escolar na escola inclusiva é de deixar claro com atos e serviços que o ensino é um e o mesmo para todos, respeitando as particularidades, as diferenças. Trata-se de um ensino participativo, solidário e acolhedor. Formas mais 
solidárias e plurais de convivência. Uma educação global, plena, livre de preconceitos, e que reconheça e valorize as particularidades (diferenças) de cada um dos outros iguais.

O gestor necessariamente tem a função de encorajar a cultura inclusiva a crescer, utilizando estratégias administrativas que propiciem possibilidades de mudança, que assumam riscos e que reforçam toda e qualquer tentativa de criar um ambiente de ensino inclusivo para todos os alunos. O gestor deve oportunizar a todos os interessados a participação nas discussões e planejamento para a construção das metas a serem cumpridas para a concretização do ensino. A medida a ser tomada pelo gestor deve estar voltada para se construir uma comunidade escolar inclusiva, baseada nos propósitos da escola, ou seja, no atendimento das necessidades de todas dos alunos portadores de necessidades especiais.

O gestor ao propor a execução da proposta de trabalho pedagógico na perspectiva inclusiva contribui para a efetivação da vivência da diversidade no contexto escolar, assim, elege como principal pressuposto a singularidade dos alunos. Priorizando, contudo, a participação da comunidade escolar acerca da construção de um sistema de educação inclusiva, por meio de uma prática reflexiva e coletiva, princípios os quais devem ser a base de todas as ações pedagógicas.

\section{AS PRÁTICAS PEDAGÓGICAS NO CONTEXTO INCLUSIVO}

O grande desafio das escolas hoje em dia é o de oferecer um ensino de qualidade, onde aconteça um desenvolvimento constante do aluno. As instituições de ensino destacam-se pelo seu papel significativo de formar e informar os alunos que fazem parte de seu cenário, onde haja um comprometimento de professores, funcionários, alunos e família, requerendo, ainda, grande esforço dos gestores em suas tarefas.

Porém, em relação aos profissionais que trabalham com a educação especial, verifica-se que estes enfrentam muitas dificuldades, principalmente no que tange as limitações de recursos, ausência de materiais e recursos didáticos que é claro facilitaria os processos de ensino e de aprendizagem. Partindo deste princípio é inegável a importância de qualificar os gestores e através destes os professores, além de garantir recursos didáticos e instalações adequadas, são os primeiros passos rumo à inclusão. 
Para isso deve-se prezar pelo investimento em capacitações dos profissionais, dando chance de uma formação que lhes assegure o preparo de que necessitam para efetivar a inclusão escolar.

Cada aluno possui necessidades especificas de aprendizagem e as instituições, bem como os gestores devem estar pedagogicamente preparados para enfrentar o desafio da inclusão. É preciso contar com estratégias auxiliares aos serviços educacionais que devem ser planejadas a fim de assegurar e garantir a educação efetiva para todos. O educando que apresenta necessidades educativas especiais necessita também de atendimento especial e claro um ambiente onde ele possa ter confiança, o estímulo e o incentivo, e as instituições devem disponibilizar estes locais.

Conhecer os alunos é o primeiro passo para que eles não fiquem à margem das novas práticas. A inclusão não significa dizer que se deve ter um ensino individualizado para os alunos que apresentam necessidades intelectuais, mas sim não se podem separar os atendimentos, nem dentro, nem fora das salas de aula.

Outra prática pedagógica a ser seguida é a instituição estar sempre aberta e flexível, à participação dos pais, inclusive nas atividades desenvolvidas pela escola, esse acompanhamento é primordial, pois os pais passam a conhecer o comportamento dos

Filhos especiais na escola, fato esse que auxiliará nas ações dos mesmos para com as crianças.

Os gestores, como qualquer profissional dinâmico, flexível e inovador precisam estar conectados com o ambiente da inclusão, eles precisam ter suas ações alinhadas com suas práticas pedagógicas, bem como agir efetivamente, porque, quem lida com alunos especiais deve, necessariamente, agir com certa afetividade, mas não se utilizando apenas de argumentos, mas também aplicações concretas.

De acordo com a Declaração de Salamanca (1994) fica claro que:

\footnotetext{
Administradores locais e diretores de escolas podem ter um papel significativo quanto a fazer com que as escolas respondam mais às crianças com necessidades educacionais especiais desde que a eles sejam fornecidos a devida autonomia e adequado treinamento para que possam fazê-lo. (...) uma administração escolar bem-sucedida depende de um envolvimento ativo e reativo de professores do pessoal e do desenvolvimento de cooperação efetiva de trabalho em grupo no sentido de atender as necessidades dos estudantes (UNESCO, p.143).
} 
A maneira com que o gestor se posiciona frente a questão da inclusão dos alunos com necessidades especiais influencia consideravelmente toda a comunidade escolar, pois ele é um líder que tem tendência a ser seguido. O bom gestor deve ter consciência de que o ensino oferecido não se pode fazer distinção de ensinos entre alunos regulares e com necessidades especiais.

Para Tesani (2010) algumas ações contribuem significativamente e para o desenvolvimento de práticas pedagógicas inclusivas e sendo assim a autora inúmera alguns passos a seguir:

\begin{abstract}
O primeiro passo, segundo suas recomendações, é construir uma comunidade inclusiva que englobe o planejamento e o desenvolvimento curricular; o segundo passo do processo é a preparação da equipe para trabalhar de maneira cooperativa e compartilhar seus saberes, a fim de desenvolver um programa de equipe em progresso contínuo; o terceiro envolve a criação de dispositivos de comunicação entre a comunidade e a escola; o quarto abrange proporcionar a criação de tempo para reflexão sobre a prática desenvolvida (TESANI 2010, p.292).
\end{abstract}

Outra postura que o gestor precisa tomar é o de encorajamento, pois tudo que é novo traz resistências como um todo, e cabe ao gestor enfrentar esta realidade, para assim diminuir a insegurança dos docentes em mudar suas percepções já formadas há anos. A criação de um ambiente escolar adequado de boa aprendizagem exige por parte da gestão

Escolar um trabalho participativo, no qual planejamentos e implementação de estratégias sejam estruturados e desenvolvidos no coletivo, com a participação de todos.

Segundo Souza (2007) é:

\footnotetext{
Através da reflexão das ações pedagógicas dos professores e demais profissionais, que os cenários são reconstruídos e resinificados dentro do conjunto de procedimentos e atitudes que o processo educacional abrange (SOUZA 2007, p.5).
}

Com isso, é necessário, que o gestor entenda o seu papel de articulador e promotor de um espaço que propicie a participação de todos os envolvidos no processo ensino e aprendizagem. 
Neste contexto fica evidente que os desafios de ser gestor são muitos, há a necessidade continua de se aprender e se de aperfeiçoar com frequência. Deve-se levar em consideração a importância da formação continuada, e ao mesmo tempo o investimento das instituições nas formações destes profissionais.

\section{CONSIDERAÇÕES FINAIS}

De acordo com estudos realizados, ficou claro que as pessoas com necessidades educacionais especiais podem e tem o direito de estudar em uma escola de ensino regular, bem como exercer sua função de cidadão. Com relação ao ambiente e ao gestor escolar, é evidente que estes estejam cientes de suas funções frente aos desafios de uma educação inclusiva, visando melhorar estruturas físicas e pedagógicas de acordo com as especificidades apontadas para as realidades do contexto inclusivo.

Entretanto para que essa realidade tão esperada aconteça de fato o gestor deve realizar seu trabalho pautado em uma gestão democrática, onde todos os envolvidos no processo ensino aprendizagem realizem um trabalho integrado objetivando a transformação da escola. É necessário também que as instituições invistam na formação para se adquirir profissionais, profissionais qualificados, pois isso vai fazer com que eles se sintam mais seguros para desenvolver seu trabalho.

Conhecendo, portanto a importância do papel do gestor nesse cenário fica claro que um gestor competente e inovador precisa estar engajado na missão da inclusão nas escolas e precisa agir de maneira que suas ações estejam atreladas com suas práticas pedagógicas, pois quem lida com alunos especiais deve, necessariamente, estar preparados, deixando de lado toda e qualquer barreira que venha a dificultar o ensino, o desenvolvimento e a atuação destes educandos.

Para que educação inclusiva seja uma realidade em nossas escolas é preciso haver uma vontade, haver um querer, uma mudança de mentalidade, construir uma escola inclusiva precisa antes de tudo haver mudança de atitude e não sempre será uma tarefa não muito fácil. Além dos gestores, depende também das políticas públicas, das instâncias administrativas, professores, funcionários e de toda a sociedade.

Entende-se que a escola inclusiva é aquela que atende às necessidades educacionais especiais dos alunos. Cabe ao professor a tarefa de conhecer essas 
especificidades e oferecer uma educação de qualidade para ele. É preciso mudar a maneira de pensar a educação, estabelecer rupturas com paradigmas já arraigados, rever valores, a fim de receber os alunos com necessidades especiais, oferecer às suas famílias a segurança de que seus filhos serão bem atendidos em suas necessidades específicas de aprendizagem.

Nesse sentido entende-se que o bom entrosamento e articulação do gestor com a equipe escolar fomentam o ensino de qualidade, sendo estes os responsáveis pelo sucesso ou pelo fracasso de qualquer ação realizada pela equipe pedagógica da instituição de ensino. O aluno com necessidades educativas especiais necessita de metodologias, estratégias diferenciadas, recursos próprios e práticas diferenciadas devido as suas especificidades motoras e de aprendizagem e cabe ao gestor promover esse atendimento.

O gestor escolar tem papel de fundamental importância neste panorama, sendo o principal agente de transformação e congraçados das expectativas do aluno, professores e pais. Ele deve promover um ambiente onde todos possam refletir a respeito "da inclusão" e proporcionar modos, formas de trabalhar explorando as potencialidades individuais. O Gestor nas escolas, precisa organizar com certa frequência um cronograma e avaliar se os encaminhamentos propostos surtiram efeito e atenderam as necessidades dos alunos, se os objetivos foram alcançados, se a metodologia, se os recursos utilizados foram capazes de provocar a inclusão e a aprendizagem.

Com Base nas análises dos referidos autores em relação ao processo educacional inclusivo e as contribuições do gestor nas escolas e com a função que irá ser úteis, para o desenvolvimento do referido processo de inclusão, considera - se que cabe ao gestor pedagógico, prover os recursos materiais e humanos necessários ao desenvolvimento do processo de aprendizagem dos alunos com necessidades especiais ; auxiliar os professores no desenvolvimento de metodologias e estratégias de ensino diferenciadas que favoreça o processo educacional inclusivo; possibilitar, no contexto escolar, momentos de reflexão com relação às práticas pedagógicas inclusivas, de forma que todos os participantes do referido processo possam participar na definição dos objetivos, no planejamento, bem como, na elaboração de propostas e planos de ação que possibilite a quebra das barreiras que estejam impedindo o desenvolvimento da aprendizagem dos alunos com necedades especiais . 


\section{REFERÊNCIAS BIBLIOGRÁFICAS}

BRASIL. Constituição Federal de 1988. Promulgada em 5 de outubro de 1988. Disponível

<http://www.planalto.gov.br/ccivil_03/constituicao/ConstituicaoCompilado.htm>.

Acesso em: 16 de nov. de 2015.

BRASIL. Estatuto da Criança e do Adolescente. Lei Federal no 8069, de 13 de julho de 1990. Disponível em <http://www.planalto.gov.br/ccivil_03/leis/L8069.htm>. Acesso em: 05 de jan. de 2016.

BOAVENTRURA, R.S.: A Gestão Escolar na Perspectiva da Inclusão. Dissertação (Mestrado em Educação). Universidade do Oeste Paulista, UNOESTE: Presidente Prudente, São Paulo, 2008.

CARVALHO, R. E. Educação inclusiva: com os pingos nos "is". Porto Alegre: Mediação, 2006. 176 p.

Diretrizes nacionais para a educação especial na educação básica. Brasília: SEESP, 2001. Disponível em: Disponível em: < http://portal.mec.gov.br/seesp/arquivos/pdf/diretrizes.pdf>. Acesso em: 22 de dez. de 2019.

FERREIRA, Nauria Syria Carapeto. AGUIAR, Márcia Ângela da S. Gestão da Educação: Impresses, Percpectivas e Compromsisos. $6^{\circ}$ edição - São Paulo: Cortez, 2008.

GARCIA, R. M. C. O Conceito de flexibilidade curricular nas políticas públicas de inclusão educacional. In: Jesus, D. M. e col. (Org.). Inclusão, práticas pedagógicas e trajetórias de pesquisa. (p.11-20). Porto Alegre: Mediação, 2007.

GLAT, R. (Org.) Educação Inclusiva: cultura e cotidiano escolar. Rio de Janeiro: 7Letras, 2007.

LÜCK, H. A evolução da Gestão Educacional, a partir da mudança paradigmática. Revista Gestão em Rede, n. 3, p. 13-18, 1997

SAGE, Daniel D. Estratégias administrativas para a realização do ensino inclusivo. In: STAINBACK, Susan; STAINBACK William (Orgs.). Inclusão: um guia para educadores. Porto Alegre: Artes Médicas, 1999. p.129-141.

PADILHA, Paulo Roberto. Planejamento Dialógico: Como construir o projeto político pedagógico da escola. São Paulo: Cortez, 2005. 
PÁEZ, Caniza de. A integração em processo: da exclusão à inclusão. In: Escritos da criança. n. 06, Porto Alegre: centro Lydia Coriat, 2001.

PENAFORTE, S. A gestão para a inclusão: uma pesquisa-ação colaborativa no meio escolar. Tese (Doutorado em Educação). Universidade Federal do Ceará. Fortaleza, 2009.

SECRETARIA DA EDUCAÇÃO ESPECIAL. Saberes e práticas da inclusão. Governo federal. Disponível em: <file:///C:/Users/USUARIOPC/Downloads/saberes\%20e\%20práticas\%20de\%20inclusã o.pdf>. Acesso em: 06 de mar. de 2020.

SOUSA, L. P. F. de. Orquestrar a gestão escolar para respostas educativas na diversidade. 2007, 113p. Dissertação (Mestrado em Educação) - Universidade do Estado do Rio de Janeiro. Faculdade de Educação. Rio de Janeiro.

TESANI, T. C. R. Gestão escolar: A prática pedagógica administrativa na política de educação inclusiva. Universidade Federal de São Carlos, São Carlos, 2010. Edições Asa.

UNESCO. Declaração de Salamanca e Enquadramento da Ação na Área das Necessidades Educativas Especiais. Ministério da Educação e Ciência de Espanha: Salamanca, Espanha, 1994. 